\title{
LOPE, DON PEDRO DE CARDENAS Y LOS CARDENIOS
}

En I929 escribia el ilustre hispanista Aubrey F. G. Bell: "On the whole we are inclined to believe that the Cardenio of Cervantes, Montalvo, Lope and Salas Barbadillo is one and the same person, and that this person is none other than don Pedro de Cárdenas [y Angulo], poet of Córdoba and author of La Estrella de Sevilla» ${ }^{1}$.

Lamento verme obligado a demostrar (en las líneas que siguen) que no hay causa ninguna para pensar que Cervantes, Gálvez de Montalvo, Lope y Salas Barbadillo designaran por Cardenio a una y la misma persona, y que hay, en cambio, muchas razones para afirmar (en unos casos con bastante seguridad y en otros rotundamente) que esa supuesta persona no puede ser el caballero cordobés, poeta y gongorista don Pedro de Cárdenas y Angulo. Tengo también que decir que, a mi juicio, hay poquísinas probabilidades de que Cárdenas y Angulo sea el autor de La Estrella de Sevilla. Bell-que hoy ya no está entre nosotros-amó a nuestra patria y trabajó con fervor sobre la historia de nuestra cultura: los españoles le clebemos estar agradecidos. Por una vez dejó libre la fantasía y el resultado fué esta cadena de errores (en parte seguicla y en parte exacerbada recientemente por el distinguido bibliógrafo don Homero Serís ${ }^{2}$ ). In nada se disminuye la gloria de tan beneméritos trabajadores por mostrar que en un punto erraron. Todos nos equivocamos, jcuántas veces!

$1 \quad M L R$, 1929, XXIV, pág. 72. V. más abajo, pág. 7o, núm. I.

2 V. más abajo, pág. 7o, niún. 4. 
UNA "APOLOGíta" GONGORINA.

En la Biblioteca Provincial de Córdoba, un manuscrito (núm. 52) ${ }^{1}$ nos revela hoy una de las muchas discusiones a que dieron lugar los versos de Góngora. Portada (y nótese la fecha, año de la muerte de don Luis):

\author{
Apologia \\ en fauor de Don luys de gongora \\ Archipoeta español \\ contra el licenciado francisco De \\ Naunarrete \\ Dirigida a Don Pedro de Cardenas y \\ Angulo \\ Caballero del Habito de santiago $y$ \\ Beynt y quatro de Cordoba \\ $\Lambda^{0} 1627$
}

Iin $4 .^{\circ:} 55$ hojas numeradas. [Fool. I]: portada, v. en blanco. I'ol. 2: dedicatoria firmada por el autor, v. ${ }^{\circ}$ en blanco. Fol. 3: comienza el texto. Fol. 52: comienza un alndicen de antores citados.

De la dedicatoria a don Pedro de Cárdenas y Angulo:

Este papel consagro a su Deydad de Vmd. (señor Don Pedro) coino único Apollo de España. Si Vud. considera que es respuesta a otros dos del licenciado Francisco de Nauarrete tan agudos como doctos, no le pareceri largo... Y si hubiere que quitar, Vnu. tiene licencia para tildarlo como Maestro del bien decir; no otro, que sería sacrilegio a tan sagrado refugio abiendo salido debaxo de tal amparo... Guarde Dios a Vind. coino este su menor Capellán le ruega.-Iil Doctor Francisco Martincz, cle Porticluelo.

Martínez de Portichuelo, segín una carta de Góngora, vió a éste en Madrid hacin el I7 de diciembre de I6Ig:

Francisco Martincz. Porticluclo tambien ha llegado, aunque de paso: he holgado de verlo, porque me lia contado de esa Sta. Iglesia "

1 Reseñado por Ramírez, de Mrcllano (núus. 7 r4 y 2.592). Me llanó la atención sobre esos artículos de $\Lambda$ rellano mi anigo E.tugenio Asensio.

2 Millé, carta 34. 
Lo de "capellán» en la dedicatoria a Cárdenas y Angulo, casa bien con el haberle contado a Góngora cosas de "la Santa Iglesia» de Córdoba.

No me voy a detener mucho en esta insulsa obrilla de Portichuelo. Baste decir que lo que discutian Navarrete y Portichuelo era el sentido de dictar ("dictó)) e inspirar (“inspirados") en los primeros versos de la Dedicatoria de las Soledades:
Pasos de un peregrino son errante cuantos me dictó versos dulce musa: en soledad confusa perdidos unos, otros inspirados.

E1 licenciado Nanarrete propuso esta dificultad en una glosa al margen: si dictauit quomodo inspirauit. Yo le respondi con otra debaxo de la suya: dictando inspirauit et inspirando dictauit. Replicó en un papel en forma: dictar e inspirar son uerbos que cntre si tienen notable opposición, porque el uerbo dictar afirma lo que el uerbo inspirar niega ${ }^{1 .}$

Hago gracia al lector de la serie de tiquismiquis entre el Navarrete y el Portichuelo, narrados por este últinı. Ein ellos se aducen autoridades de poetas latinos y castellanos y la del mismo Góngora. ¿Implica inspirar una unoción o impulsión que en los poetas y profetas los excite y mueva a que digan dialectos, conceptos, pensamientos, discursos y palabras de que ellos como inspirados y como poetas y profetas sean cansas principales"? ¿O habrá de entenderse que el Espíritu Santo (en literatura cristiana) o Apolo y las Musas (en pagana) sean las unicas causas principales, y ellos (upoetas y profetas") sólo unos "meros instrumentos»? ${ }^{2}$. Ahí estaba el quid, y ahí trabaja y suda largamente el gran Portichuelo.

Esta Apologia muestra una vez más hasta qué punto los que se consideraban discípulos estaban dispuestos a saltar en defensa de Góngora. Pero quizá yo no hubiera hablado aquí de ella si no fuera porque nos of rece algún dato nuevo sobre

1 rol. 3.

2 liol. $32 \mathrm{v}^{\circ}$ 
don Pedro de Cárdenas y Angulo. Il auténtico interés que este caballero mostró por la cultura y en especial por la poesía, su posición de Mecenas en los círculos literarios cordobeses, y sobre todo el haber protegido a Góngora e intervenido personalmente en la primera salida al mundo de las Soledades y el Polifeno, merecen tola nuestra atención. Pero desde el siglo pasado y (con otro brote súbito) en el uuestro, don Pedro de Cárdenas y Angulo ha excitado la curiosidad de la crítica por otros motivos. Estos otros motivos, como vamos a ver, no son sino puras fantasmagorías.

Cárdenas y Angulo inutor de "LA ESTRELLA DE SEVILLA"?

Bell ' fué quien hizo el gran descubrimicnto: en los versos últimos del desglose (arrachement.) publicado por FoulchéDelbosc ${ }^{2}$ de La Estrella de Sevilla, se menciona a un Cardenio cono autor de la obra; en las Rimas de don Antonio de Parcdes ${ }^{3}$ se llama varias veces Cardenio a don Pedro de Cárdenas y Angulo, el cual en colaboración con don Antonio de Parecles, había compuesto una comedia (de la que se reproduce un fragmento en dichas Rimas). Luego no cabe duda: don Pedro de Cárdenas es el autor de La Estrella. Así concluye Bell, y recientemente don Homero Serís ${ }^{4}$ considera tal conclusión como definitiva ${ }^{5}$.

1 The Author of "La Estrclla ile Sevilla", en Rev. Hisp., I.IX, I923, 200-300; Who "ias Cardenio? y The Aluthorship of "La Estrella de Sevilla", en Mod. Lang. Rev., XXIV, 1929, 67-72 y XXVI, I931, 97-98.

- "La Estrella de Scvilla", id. critique publićc par R. FoulchéDelbose. (Extrait de la Rev. Hisp., XLVIII, 1920.)

3 Córdoba, 1622. Existe una fiel reimpresión moderna cuidada por Antonio Rodriguez Moñino, Valencia, 1948, que es la que utilizo.

- Un soneto del autor de "La Estrella de Sevilla" y Don Pedro de Cirdenas, mecenas y editor de Góngora, en Nucva Rev. de Filol. Hispánica, VII, 1953, 433-439 y IX, 1955, 22-32. Salvo aviso, cito siempre este segundo artículo.

- Claro que otros muchos lian hablado despućs sobre la autoria 
Desgraciadamente, el negocio no es tan mollar. De una parte, porque Cardenio, como nombre poético, no es del todo infrecuente. Y de otra, porque nada, en lo que conocemos de la poesía de Cárdenas y Angulo, recuerda el estilo del autor de La Estrella. Además, esta comedia es de un sevillanismo apasionado, que constantemente viene a la pluma del dramaturgo. Pero sólo una vez, y muy de pasada, sale algo cordobés en ella: de don Gonzalo de Ulloa, personaje secundario, se nos dice que es "un cordobés Cid»; eso es todo.

La Estrella, tal como ha llegado a nuestras manos, parece obra de un hombre de poca fantasía poética, pero con gran experiencia de las tablas. Cuando el autor quiere hacer pinitos líricos el resultado es poco loable. En cambio, los tercetos de Cárdenas y Angulo a la muerte de Paredes son pulcros y finamente espirituales. El autor de La Estrella parece un practicón teatral, que esta vez dió genialmente en el hito; Cárdenas y Angulo es el noble y rico caballero delicadamente atraído por el mundo de la poesía. Quizá algún día se descorrerá el velo que oculta al autor de La Estrella de Sevilla: me extrañaría unuchísimo ver aparecer detrás el nombre de don Pedro de Cárdenas y Angulo. En último rigor crítico no puedo negar la posibilidad de que sea él el autor; pero me parece poquísimo verosímil.

de La Estrella y casi nadie sigue la opinión de Bell. Pero el hecho de que el señor Serís haya publicado recientemente dos artículos sobre don Pedro de Cárdenas, y en ellos considere como verdad definitivamente conquistada el "descubrimiento" de Bell, me obliga a tratar aqui este tema, aunque sólo lo hago para decir que a mi juicio es muy poco verostmil que Cárdenas y Angulo sea el autor de dicha comedia. Una bibliografia suficiente (hasta 1939) puede verse en el prólogo de J. M. Hill a la edición de La Estrella, con notas y vocabulario, por F. O. Reed y E. M. Dixon, Boston, I 939. 


\section{¿CUándo NaCió Y CUÁNDO MURIó CARDENAS Y ANGULO? TESTIMO- NIOS EN PRUEBAS DE LIMPIEZA.}

Mientras tanto sí puedo deshacer algunos errores acerca de la vida de don Pedro.

E1 señor Serís 1 , llevado por una serie de desventuradas conjeturas, "mata" a don Pedro en el año I624. Pero el lector ha visto ya que en 1627 estaba aún vivo, lo bastante para que Portichuelo le dedicara la $A$ pología que hemos reseñado.

Ramirez de Arellano había dado como fecha de la muerte de Cárdenas el año I645; quizá se basaba únicamente en que en ese año la viuda y los hijos presentaron a don Luis Méndez de Haro una obra que don Pedro había dejado inédita. Ramírez de Arellano estaba, sin embargo, más cerca de la verdad que el señor Serís.

Si abrimos la "Primera parte" del "Segundo tomo" de los comentarios gongorinos de Salcedo Coronel, veremos que, en efecto, poco antes de 1645 don Pedro de Cárdenas estaba aún vivo. Ese volumen (que contiene los comentarios a los sonetos) se publicó en I645; pero los preliminares nos llevan a $1643^{2}$. Comentando el soneto que empieza "Hojas de inciertos chopos el nevado", nos dice Salcedo Coronel:

Escriuió Don Luis de Góngora este soneto a Don Pedro de Cárdenas y Angulo, Cauallero de Córdoua y dignamente hijo suyo por el ingenio que le haze no menos claro que su generosa sangre ${ }^{3}$.

Naturalmente, "que le haze" indica una persona viva. $\mathrm{Y}$ todo se confirma, sin posible asomo de duda, en otro pasaje del mismo tomo de los comentarios, donde, al hablar de cor-

1 Art. cit., pág. 27.

2 Obras de Don Luis de Gongora comentadas..., tomo segundo [en la anteportada: Segundo tomo... Primera parte], Madrid, 1645. Aprobación: 17 de abril 1643 .

- Ibid., pág. 129. 
dobeses ilustres, después de haber alabado a los de otros tiempos, dice el autor lo que sigue:

Esta felicidad no sólo la conocieron los antiguos, y nuestros mayores en los sujetos que alcanzaron, pero oy la admiramos en los que florecen con tanta estimación de los professores de la facultad Poética, hallándose en aquella ciudad, entre otros eminentíssimos en esta professión, Don Pedro de Cárdenas y Angulo, Don Pedro de la Cerda y Don Luis Godoi Ponce de León, nuestro amigo, no menos ilustres por el ingenio que por su generosa sangre ${ }^{1}$.

Por desgracia, el señor Serís no sólo ha fantaseado la fecha de muerte de don Pedro de Cárdenas, sino la de nacimiento. Supone ${ }^{2}$ que ració en 1549 ó 5550 . He aquí, primero, algunos datos, inéditos, de pruebas de limpieza, para ingreso en órdenẹs militares, existentes en el Archivo Histórico Nacional de Madrid:

Expediente de don Pedro de Cárdenas y Angulo (Santiago, número I.535), año de I609. El primer testigo, Francisco Garcia de Berlanga, dice, al responder a la séptima pregunta, que el pretendiente nes hombre moço, de edad de veynte $y$ quatro años, agil, que sabe y puede andar al caballo, y este testigo le a bisto $y$ be en ellos muy de ordinario y sabe que los tiene suyos proprios». De veintidós testigos. veinte contestan a la pregunta relativa a la edad. Conocida es la imprecisión de estos datos en el siglo Xvir. El $20^{\circ}$ dice que el pretendiente tendrá de 24 a 28 años; el $3 .^{\circ}$, de 24 a 25. De los demás, uno le adjudica 26 años; cuatro, 25; cuatro, 24; tres, 23; uno, 20. Sacando la media resulta, como apreciación de conjunto, la de 24 años. Don Pedro deberia haber nacido, según esto, hacia 1585.

Expediente de don Francisco de Góngora y Argote (Santiago, nímero 3.497), año de 1622. Declara alli el propio don Pedro de Cárdenas y Angulo (su declaración comienza al recto del penúltimo folio). $\mathrm{Y}$ a la segunda pregunta contestó entre otras cosas "que es de edad de treynta y çinco años, poco más o menos». Según esta dlcclaración, don Pedro habria nacido hacia 1587.

3 Ibid., pág. 259.

2 Art. cit., págs. 27 y 29. 
Lo misino las declaraciones de los testigos en el expediente de don Pedro, que la del propio don Pedro en las pruebas del sobrino de Góngora, nos llevarían a los alrededores de I586, año más, año menos.

¡FSOS POETAS!: LA PARTIDA DE BAUTISNIO.

Iis costumbre corriente de los poetas, lo mismo los de tiempos pasados que muchos de hoy, con los que he tenido amistad, el quitarse años. Esto y la imprecisión, el "sobre poco más o menos" de los testigos del siglo XvIr, me hicieron tomar precauciones. Escribi a mi amigo el diligentísimo $\mathrm{y}$ erudito investigador de los archivos cordobeses don José de la Torre, pues imaginaba yo que en sus lecturas habría anotado la fecha de nacimiento de Cárdenas y Angulo. Con su peculiar generosidad, don José de la Torre me comunicó los siguientes datos: Pedro, hijo de don Hernando Arias de Saavedra y de doña Ana de Caicedo, fué bautizado el I3 de septiembre de 1577 en la parroquia de Santiago (archivo de dicha parroquia, libro $\mathrm{I}^{\circ}$ (e bautismos, folio ror).

¿Cómo es posible? ¡Don Pedro de Cárdenas y Angulo se quitaba nada menos que unos diez años, en su declaración en el expediente de don Francisco de Argote y Góngora! i广 cuánto se "equivocaban" también los testigos de las pruebas del propio don Pedro!

I,os poetas contemporáneos míos se han quitado siempre uno, dos, cuando mucho tres años. Don Pedro de Cárdenas y Angulo supera pintorescamente todas las "marcas" en ese pueril empeño de prolongar juventud.

Ramírez de Arellano obraba, pues, bien al barruntar que Cárdenas y Angulo labría nacido en el último tercio del siglo Xvi. Iil señor Serís comete un crror de veintiocho o veintinueve años al suponer que nuestro poeta nació en I549 ó I 550 .

Debo pedir disculpa por tener que tratar ahora de una an- 
tigualla que debería estar arrumbada desde hace mucho tienpo. Si lo hago es porque lo mismo Bell que el señor Serís ${ }^{1}$ dan de nuevo en ella.

En el Ensayo de Gallardo (tomo III, col. I086), al hablar de las Rimas de don Antonio de Paredes, se lee: "¿Tendrá algo que ver con el Mecenas don (Antonio) [Pedro] ${ }^{2}$ de Cárdenas, cuyo nombre poético era Cardenio, el Cardenio del Quijote?"

Lo primero que debemos tener presente es que, hasta ahora, no hay la menor prueba de que la historia de Cardenio tuviera base real. Me extraña, por otra parte, que los eruditos que han tocado esta cuestión no hayan visto cuán poco probable es que Cervantes se basara en un hecho contemporáneo, chyos protagonistas vivieran aún: el tema (en la dóbie historia de Luscinda y de Dorotea) era delicado. Si pensamos que Cervantes se apoyaba en una historia reciente ( $y$ lo dudo mucho), hemos de imaginar que de ningún modo lo haría sin cambiar totalmente los nombres ${ }^{3}$, y grandemente los pormenores y los lugares.

Es bien imprudente además (luego lo vamos a comprobar) querer ver Cárdenas detrás de todo Cardenio. Dos veces ha empleado Cervantes ese nombre, las dos para personajes importantes: uno, el Cardenio del Quijote; otro, el Cardenio

1 Bell, MLR; 1929, XXIV, pág. 72; Seris, NRFH, VII, 1953, página 137 .

2 Evidente error wecánico (se ha cruzado el nombre de pila de don Antonio de Paredes); el nombre de don Pedro de Cárdenas aparece correctamente citado en esa misma columna y en las dos anteriores.

3 Se ha observado que al comienzo del cap. XLII de la primera parte del Quijote, cn la primera impresión, se lee "Don Antonio" en vez de "Cardenio". Rodríguez. Marín piensa que se trata de nua errata. Extraña errata, por cierto. Se podria pensar que "Don Antonio" fué el nombre del personaje en la primitiva redacción, y que Cervantes lo cambió luego por el de "Cardenio", corrigiéndolo en todos los lugares menos en éste, que se le liabrla olvidado. Si fuera asi tendrianos alú un indicio más contra la identificación de Cardenio como don Pedro de Cárdenas. 
de La Entretenida. Este último es, sin duda, el papel principal de la comedia: es un estudiante apicarado que suplanta la personalidad de don Silvestre de Almendárez, que viene de las Indias para casarse con una prima suya. ¿Hemos de pensar también que este Cardenio oculte otro Cárdenas? Absurdo. $\mathrm{Y}$ si habia usado una vez hacia $1603^{1}$ el nombre Cardenio para designar, poéticamente, a don Pedro de Cárdenas y Angulo, ¿no es muy extraño que, vivo aún este caballero, en I6I5 empleara Cervantes el nombre de Cardenio para representar a un tunante estafador?

Bell y Seris se han basado para sus construcciones hipotéticas en una nota de Rodríguez Marín a su edición del Quijote:

Cardenio es un Cárdenas de Córdoba; don Fernando, don Pedro Girón, hijo segundo del primer Duque de Osuna...; Dorotea, doña Maria de Torres, que fué seducida por don Pedro... Estos amores datan de los años 1582 y 1583 .

No es asunto mío ahora la verdad o falsedad de estas afirmaciones de Rodríguez Marín. No me interesan sino por esto: porque en ellas se, basan todas las hipótesis de Bell y también las del señor Serís. Pero el lector sabe ahora muy bien que entre 1582 y 1583 don Pedro de Cárdenas y Angulo no pudo tener relación ninguna con esos amores. De los principios de I582 a los finales de 1583 pasó de tener cuatro años a tener seis. Edad un poquito demasiado temprana para amores o amoríos.

\section{Poetas Cardenas gue No SON DON PEDRO DE CARDENAS Y AN- GULO.}

¿Por qué la fantasía, sin freno, ha ido a estrellarse tantas veces en la persona de don Pedro de Cárdenas y Angulo, de este caballero cordobés que llevó en fecha temprana a Madrid

1 Fisa feclia se puede calcular, aproximadamente, para la redacción de la historia de Cardenio, en el Quijote. Año más o menos, no tiene ahora para mi propósito importancia alguma. 
el Polifemo y las Soledades? ¿Que en la Araucana (1569) había dos quintillas firmadas por don Pedro de Cárdenas? ¡Pues ya eso bastaba para que Cárdenas y Angulo hubiera nacido hacia 1550 !

Ahora, conocida ya la fecha de nacimiento de Cárdenas y Angulo, sabemos que no puede ser el de la Arancana, por la sencilla razón de que nadie escribe quintillas antes de nacer. Por la misma razón (de peso), no puede ser el nuestro el don Pedro de Cárdenas que contribuye con otras dos quintillas en la Historia y relación verdadera..., de López de Hoyos (Madrid, I569). (Es probable que ambos quintillistas sean una sola persona.)

Pero los Cárdenas a quienes les soplaba la musa eran, parece, muchos. $\mathrm{Y}$ no perdamos de vista que detrás de todo Cárdenas, poeta, hay, en potencia, un Cardenio (si bien nos engañaríamos pensando que detrás de todo Cardenio ha de haber, por fuerza, un Cárdenas). He aquí algunos otros poetas Cárdenas:

Iñ I598, don Mateo Pérez de Cárdenas publica un soneto en los preliminares de La Arcadia: contribuye con otro para La Hermosura de Angélica (1602); este amigo de I,ope publica también un soneto en la Historia evangélica de la vida... de Christo, de Juan de Arce Solórzano (Madrid, I605) ${ }^{1}$. - Un Licenciado Miguel de Cárdenas Calmaestra publica en 1604 un soneto en la segunda parte del Guzmán de Alfarache.-Un don Juan de Cárdenas escribe un soneto para el Estilo de servir a principes, Madrid, 1614, de Yelgo de Vázquez ${ }^{2}$.En Sevilla, en 1616, publica fray Bernardo de Cárdenas el conocido soneto "Ensilla, Sancho amigo, a Rocinanten; este poeta, fraile basilio, fué autor de varios autos teatrales; Bonilla San Martín sugirió que fray Bernardo podria ser el autor de La Estrella de Sevilla ${ }^{3}$.-

1 Pérez Pastor, Bibliogr. madril., núm. 90r, donde se reproduce este último soneto.

2 Ibid., núm. 13r3.

3 Luque Faxardo, Relación de las fiestas que la Cofradia de San Pedro ad Vincula celebró... a la Purissima Concepción, Sevilla, I6r6 (Escudero y Perosso, núm. 1074); comp. Rivad., XXXV, núm. 92. V.: Menéndez Pelayo, Estudios sobre el teatro de Lope, IV, Madrid, 1923, pág. 270, nota (de Bonilla, quien se basa en Sánchez Arjona, Noticias referentes a los anales del teatro en Sevilla, Sevilla, 1898). 
En 1623, en el Encomio de los ingenios sevillanos se imprimen poesias, ya graves, ya jocosas, de un Bernardo Luis de Cárdenas; no parece caber duda de que era sevillano; desde luego era muy amigo del colector del libro, Juan Antonio de Ibarra, quien le elogia muchas veces y con mucho calor ${ }^{1}$. - También entre los poetas sevillanos, alaba en 1627 el Panegirico por la poesía a un don Garcla de Cárdenas '. 1Habia, pues, bastantes poetas Cárdenas en Sevilla a principios del siglo xvir!: no deja de ser interesante dado el sevillanismo de La Estrella de Sevilla, obra de un Cardenio.

En fin, a poco que se rasca, surgen poetas Cárdenas por todas partes. Es mucha valentía imaginar que cualquier poeta Cárdenas, no bien identificado, haya de ser don Pedro de Cárdenas y Angulo. Nótese que al convertir a éste en autor de La Estrella de Sevilla se salvan osadamente de un tranco dos saltos hipotéticos. A saber: $.^{\circ} .^{\circ}$ Que el Cardenio autor de la obra ha de ser un Cárdenas; $2 .^{\circ}$ Que ese Cárdenas (entre tantos Cárdenas) ha de ser ni más ni menos que don Pedro de Cárdenas y Angulo. Aunque ocurra precisamente que Cárdenas y Angulo (por todo lo que sabemos de él y ha sido visto ya, o se verá aún, en el presente artículo), no tuvo las condiciones que se esperan en el autor de La Estrclla de Sevilla.

Queda aún otra perspectiva muy importante: hay muchos Cardenios en literatura española que no corresponden a ningún Cárdenas.

Cardenios que no son Cardenas.

He aquf una lista, en orden aproximadamente cronológico, de algunos Cardenios que es necesario tener en cuenta en la discusión de estos problemas ${ }^{3}$ :

1 El Encomio ha sido reproducido primorosamente en 1950 por el ilustre bibliófilo don Antonio Pérez Gómez.

2 Ed. Cardenal de Iracheta, pág. 7o (= Rev. de Bibliogr. Nac., II, I94I, pág. 334).

3 Abreviaturas especiales para esta lista: F.-D. = La Estrella de Sevilla, édition... par R. Foulché-Delbosc, Extrait de la Revue Hispanique, XLVIII, 1920.-M.-B. = Morley and Bruerton, The Chronology of Lope de Vega's Comedias, x940.-Morley Ps. = Morley, The 
r. Eu El Pastor de Filida de Gálvez de Montalvo (1592), Cardenio es un pastor rico; aunque es menos músico que enamoradon, canta una vez una canción (N. B. Aut. Esp., VII, 556).

2. En el romance "Después de mañana, moças" (de los últimos años del siglo XVI, según F.-D., 36, nota 2). Cardenio figura allí como la propia persona que canta. Son unuy verosimiles los argumentos de EJM (IV, págs. X-XII), según los cuales este romance podria ser de Iope, y Cardenio, por tanto, representar en él al propio poeta.

3. En La escolástica celosa, de Lope (I 596-I602). En el Cardenio, estudiante, protagonista de esta obra, creo, a pesar de la opinión, siempre digna de tenerse en cuenta, del ilustre Morley (Ps., 438), que hay 'rasgos evidentes del propio Lope. Coincido con Juliá (EJMI, IV, página $X V$, al final de la nota 3 ) en considerar que este personaje ofrece analogías con el Fernando de La Dorotea. No es que aquí Cardenio represente a Lope, pues Lope fué traicionado por Filis y Cardenio, tan sólo se cree, equivocadamente, traicionado por Celia; pero la furia de los celos, la amargura del abandono, es la misma, y así Cardenio prorrumpe en dos sonetos de los de la ruptura con Filis (por lo menos del tipo de éstos), uno aparecido ya en La Arcadia (Rivad. XXXVIII, II5), y el otro, de las Rimas (O. S. IV, 285). Cardenio unuestra un dolorido apasionamiento, que es el del Lope juvenil y el del Fernando de La Dorotea.

4. En La Arcadia, de Iope (1598). Miorley (Ps., 437) ha señalado muy bien el carácter animado y bromista de este Cardenio, a quien en la novela Lope llama unas veces asi y otras "el Rústicon: "Siempre-dice uno de los pastores-he tenido yo a Cardenio por hombre de agradable naturaleza, jovial y alegre, y que ignora lo que quiere, y sabe lo que ignoramos* (Rivad. XXXVIII, i $12 b$ ). Una vez canta una canción "a su gracioso modo", es.decir, muy urústica" (Ibid., I I I(I2). Poeta natural, el autor nos le representa, otra vez, caballero usobre un flacó asnillo, todo enramado de urboles y cubierto de rosas, un tamboril destemplado, a cuyo son cantaba, no las grandes victorias de los dioses ni las transformaciones de Júpiter, sino las fábulas y apólogos de las ranas y los gallos, cantando los amores del cuervo y la paloma, lo que le dijo el ruiseñor a la oropéndola y el cernícalo a la calandria (Ibid., 67). Es como el genio de lo natural, de lo jovial, de lo inocente, de lo fuerte, de lo sano. Lope, no cabe duda, nira con enorme simpatia a esta criatura suya (véase más abajo, núm. 5).

Pseudonyms and Literary Disguises of Lope de Vega en "Univ. of Calif. Pub. in Modern Philology*, XXXIII, núın. 5, 1951, págs. 421 484.-EJM = Iope de Vega.... Obras dramáticas escogidas, edición... por Eduardo Juliá Martínez. (Cito solamente el tomo II, $1934 \mathrm{y}$ el IV, r935.) 
¿Hay en ella rasgos autobiográficos? Es preciso tener en cuenta que en la novela existe un pastor Belardo que a veces representa a Lope (Ibid., II 7 a). Cardenio no es aqul Lope, pero es una apetencia de su alma ${ }^{2}$.

5. Carácter parecido al núm. 4 es el dramáticamente poco importante Cardenio de El Marqués de Mantua, de Lope (1598-1603, M.-B.). Figura sólo en un par de escenas de caza, en el acto segundo. Su intervención se reduce, de una parte a recitar un monólogo interrumpido dos veces, en liras de seis versos (allá los cortesanos sigan sus locuras, a él le bestará el amor de su Alcida), y de otra, a burlarse, a lo rústico, de dos cazadores del marqués y responder a unas preguntas del marqués mismo.

6. En El mayorazgo dudoso, de Lope (1598-1603, M.-B.), absurdamente, figura de dos modos distintos el nombre de Cardenio: de un lado como seudónimo que adopta el príncipe Lisardo, fingido jardinero (Acad. N., VII, 47I), y de otro, como verdadero nombre de un pastor (Ibid., 487 y sigs.). Aunque este último es un personaje de poca importancia, es el de más relieve del grupo de rústicos (Cardenio, Celio, Fineo, Corinto): enamorado de.Clavela, siente celos de Iuzmán, etc.

7. En La mocedad de Roldin, de Lope (r599-1603, M.-B.), hay un Cardenio, rústico, de escaso interés: es uno de los mozos de otra aldea que se pelean con los del lugar donde vive Roidán (Acad., XIII, 227-228).

8. Una Belisa llora la dureza de un Cardenio en un romance de antes de 1605 (Hill, Revue Hisp., LVI, 1922, págs. 420-422).

9. Dos romances en los que un Cardenio se lamenta de la no correspondencia de Belisa, y una carta en liras, de Cardenio a Celio, las tres piezas en el ms. 3915 de la Nacional. Los romances podrfan ser de Lope; por lo menos hay en ellos rasgos estilisticos y afectivos que recuerdan al gran poeta ${ }^{2}$. El estilo de las tres piezas va bien con los últimos años del siglo XVI, o con los primeros del xVIr.

ro. El Cardenio del Quijote (r605).

II. Un Cardenio en la comedia Don Quijote de la Mancha, de Guillén de Castro (¿hacia 16ro?), imitación de la historia de Cardenio,

1 Cabe preguntar si este Cardenio tendrá algo que ver con el Mateo Pérez de Cárdenas que contribuye con un soneto en los preliminares de la misina Arcadia (Rivad. XXXVIII, 46 b). Otro so-i neto de este amigo de Lope, en La Hermosura de Angelica (1602).

2 Así lo ha sugerido Eduardo Juliá (Obras dramáticas..., de Lope, t. IV, Observaciones prelimninares, páginas $\mathrm{X}-\mathrm{XV}$ ). Comp. Rev. Hisp. LVI, págs. 406-419. 
I,uscinda, don Fernando y Dorotea, con muchos elementos variantes: el Marqués (= don Fernando) y Cardenio habfan sido trocados cuando niños, etc. (V. La Grone, The Imitations of "Don Quirote in the Spanish Drama, Filadelfia, 1937, págs. 9-12).

12. La fábula de Perseo, de Lope (hacia I6I I). En ella, Cardenio, un pastor poeta, representa indudablemente al mismo Lope, al pedir el puesto de cronista, cosa que hizo el dramaturgo repetidamente, y que varias veces piden por él personajes de sus comedias (EJM, II, págs. XXv- $x \times x$ y Morley, Ps., 436-437, 442, 443 y 458). Ni esos personajes, ni el presente Cardenio, representan totalmente a Lope; le representan, si, en cuanto pretendiente de dicho cargo, y pueden tener algún otro rasgo próximo: asł el Cardenio de La fábula de Perseo, es pastor, pero también poeta.

13. La Arcadia, comedia de Lope, que procede de su misma novela pastoril. En la comedia, el carácter de Cardenio tiene un gran desarrollo. Alll era un pastor jovial y bromista; aqu sus bromas tienen mucha importancia para la acción: colocado tras la estatua de Venus, habla fingiendo vaticinios de la diosa, con lo que logra impedir un matrimonio, etc. Salvo el de su ingenio sobresaliente, no se ve rasgo én él que pueda recordar la persona de Lope (véase Morley, Ps., 437).

14. Un Cardenio en La firmeza en la desdicha, de Lope (16ro-12). Es un rústico enamoradizo; recita un soneto grotesco.

15. En El caballero puntual, de Salas Barbadillo (primera parte; publicada en r6r4; estaba ya escrita a mediados de 16r3), figura en el capitulo VIII un Cardenio aMarcial de nuestra edad,, que recita cientoún epigramas. Ese Cardenio es el mismo Salas Barbadillo, pues la mayor parte de dichos epigramas pueden leerse entre los ciento noventa que publicó como suyos en sus Rimas castellanas, impresas en I6r8. Inmediatamente antes, en el mismo capttulo de El Caballero puntual, otro poeta al que llama Albanio, recita un poema llamado el Escollo, el cual se halla asimismo en las mencionadas Rimas. Tales personajes, en la novela, no figuran más que como autores de esas composiciones: son, pues, como seudónimos de Salas Barbadillo.

16. En Virtud, pobreza y mujer, de Irope (1612-15), la protagonista; Isabel, disfrazada de moro, es llamada Cardenio (Rivad. LII, $230 b)$.

17. Personaje importante en La Entretenilla, una de las Ocho comedias publicadas por Cervantes en 1615. Cardenio, estudiante apicarado, suplanta la personalidad de don Silvestre de Almendárez, que viene de las Indias para casarse con una prima suya.

Se han citado aún otros Cardenios: En un romance del mismo manuscrito 39 r 5 (véase el núm. 9): es una ensalada, que en la parte de romance muestra la imitación del estilo de Góngora. No ofrece inte- 
rés para el problema de Cardenio.-Un Cardenio, labrador vicjo (sin importancia) en Alejandro el Segundo, comedia atribuda a Lope (Acad. N.. I), atribución desautorizada por Morley-Bruerton.-Un Cardenio en La Vandolcra de Flandes, de Baltasar de Carvajal (F.-D., 36, nota 2).- Uno en Cegar para ver mejor, de Ambrosio de Arce (Ibid.).-Figura un Cardenio ell el reparto de La ninfa del cielo, de Tirso, pero no aparece luego en el texto (N. B. Aut. Esp., IX, 438).En la novelita No hay desdicha que no acabe, del siglo xvI, Cardenio es un portugués de Setúbal ${ }^{1}$.- Un criado de nombre Cardenio se menciona en El celoso prudente, de Tirso (Rivad. V, 630 c).-Drescindo de otros Cardenios, evidentemente más tardios.

HIPOTESIS DE BELL DESMORONADAS: IAS DE GALVEZ DE MONTALVO Y SALAS BARBADILLO.

De los cuatro Cardenios que Bell afirmaba-según vimos al principio-que debian de ser una y la misma persona (la de don Pedro de Cárdenas y Angulo) podemos quitar ya, rotundamente, el de Gálvez de Montalvo (núm. I). Por esta sencilla razón: este Cardenio estaba ya en letras de molde en I582, es decir, cuando Cárdenas y Angulo tenfa unos cinco años.

$\mathrm{Y}$ podemos tachar también, con segura decisión, el de Salas Barbadillo (núm. I5). Hemos visto que este Cardenio de I6I4 representa al mismo Salas Barbadillo. Claro está que representando a Salas Barbadillo no puede representar a Cárdenas y Angulo. Ni tampoco puede coincidir con el de Gálvez de Montalvo, porque cuando en 1582 se imprime la novela de este último, Salas Barbadillo era un niño de teta.

1 Citó este Cardenio Bell, MLR, XXIV, 1929, pág. 68. Esta novelita, carente de valor literario, está en Rivad., XXXIII, págs. 5 7- $^{-}$ 524 (comunicación de Rodríguez Moũino). 
I.OS CARDENios DE I.OPE.

Si repasamos la anterior lista nos quedamos admirados del considerable número de Cardenios que pertenecen a I,ope: números $3,4,5,6,7,12$, I3, I4 y I6. Nada menos. Se dirá: jla obra de Lope es tan larga! Cierto; pero no deja de ser raro que de una lista de $I 7$ Cardenios fechables, nueve pertenezcan a Lope de Vega. Además de esos Cardenics, seguranente lopescos, el ser Lope tan "cardenistan hace aún mas probable que entre los cinco ya sospechosos de lopismo (núms. 2, 8, y las tres piezas del número 9), haya varios que procedan también de la pluma del grande y fecundo poeta. Los argumentos de Juliá hacen verosímil que el núm. 2 sea de Lope, así como los dos romances del núm. $9^{1}$.

En resumen, si de I7 Cardenios aproximadamente fechables, nueve desde luego son seguramente de Lope (nús de la mitad), es probable que sean suyos nada menos que I4 (más de las cuatro quintas partes).

Recordemos el origen de todo este problema. En La Estrella de Sevilla, según el udesglose" descubierto y publicado por Foulché-Delbosc (desglose cuyo título general y cuyos títulos de los folios la atribuyen a Lope, exactamente lo mismo que ocurría en la "suelta" conocida antes), aparece como autor, en los versos del final, un Cardenio:

$$
\begin{aligned}
& \text {...esta tragedia os consagra } \\
& \text { Cardenio, dando a La Estrella } \\
& \text { de Sevilla, eterna fama... }
\end{aligned}
$$

Foulché-Delbosc exclamaba jubiloso: "...no puede ser de I,ope, porque está firmada Carienio, seudónimo que Lope no ha

1 No me parece tan feliz la argumentación de Juliá por lo que toca a la carta en liras del mismo nim. 9; sin embargo, hay que reconocer que nada hay en dicha carta que excluya el que Iope sea su autor. 
usado jamás". Afirmaciones de cse tipn, en filología, son siempre imprudencia temeraria. Eduardo Juliá Martínez ha demcstrado de manera brillante, que Lope, por lo menos una rez, se representó con el nombre de Cardenio (en el Pcrsco, nuin. I2 de mi lista). Morley ha añadido luego pruebas irrecusables a la demostración de Juliá. $\mathrm{Y}$, naturalmente, si Lope se pudo llamar Cardenio en el Pirseo, no hay motivo para que no se pudiera llamar Cardenio al final de La Estrella de Sevilla.

Repasemos ahora la lista a.nterior. Ya hemos comprobado que Lope demuestra una afección especial al nombre de "Carclenio", no de los más frecuentes a principios del siglo Xvir, ni aun después de la elorme divulgación del Quijote. Inmediatamente vemos que ese gusto por el nombre de Cardenio nace en I,ope bastante pronto, por los años anteriores al final de siglo; de esa época, o poco después, son varios de los Cardenios auténticamente lopescos, uúms. 3, 4, 5, 6 y 7 , y probablemente los nuims. 2,8 y 9.

Junto a tal acumulación de Cardenios de Lope, por esos años, conviene considerar el carácter de esos personajes. Uno (núm. 3) es un joven estudiante, apasionado, vehemente, sincerísimo, rasgos con que Lope se idealiza a si mismo en los trances de la ruptura con Filis. Este Cardenio no es un retrato sutobiográfico de Lope: pero es psicológicamente un hermano del Lope amargo de amor y de traición. Los Cardenios núms. 4, 5, 6, 7, I2 y I4, son rústicos, la mayor parte pastores. Lr,pe sentía en Cardenio la procedencia de cardo ( parece .., Cardenio amigo, tu canción a tu nombre, porque en mi vida he oído cosa más rústican, se dice en La Arcadia ${ }^{1}$ ): en todos esos Cardenios surge, más o menos, el contraste naldea" y "corte", unaturalezan y "artificion, y la simpatía de Lope se vierte en favor de cada uno de esos Cardenios pastores: no cabe duda de con cuánto placer contempla al núm. 4, que representa la alacridad de las fuerzas naturales; creo que en'

1 Rivad., XXXVIII, II2 6. 
cierto modo se ve representado por el 5, cuyo monúlngo es un tratamiento más del tema del "menosprecio de cortc»:

\author{
Iil caballero cace \\ y el que es pastor su ganadillo abrace.
}

$Y$ no cabe ducla-como hemos visto-de que parcialmente se representa en el Cardenio I2. Más aún: se puede decir que no hay un solo Cardenio creación suya, ni aun de los dramáticamente más insignificantes, que no esboce con algo de preferencia. (Cuando, en Lope, en un grupo de villanos hay un Cardenio, es éste, relativamente, el más desarrollado del grupo.)

Hay en la persona de Lope (tan nuúltiple) una veta de humildad, de reconocimiento de sin molcsto estado, que aflora con inumerables testimonios: el "parva propria", etc. ¿No es él, acaso, el pobre pastor de los sonetos del "manso»? Iray. una afinidad espiritual de Lope con sus Cardenios; y alguno de estos Cardeuios 1lega, momentáneamente, a representarlc.

Esto no resuelve, claro está, el problema de La Estrella de Scvilla. Pero nos haría ser sumamente cautos antes de rechazar la atribución a Lope si el principal argumento fuera la aparición de ese Cardenio de los versos finales. Cardenio la sido alguna vez seudónimo de Lope; toda una serie de Cardenios lopescos guardan afinidades con una veta de la psicología de su creador; hay por lo menos otro Cardenio hermano gemelo del apasionado Lope juvenil (tras Filis), y, en fin, I,ope es un verdadero especialista de Cardenios, entre la relativa escasez de este nombre en la literatura de finales del siglo xvi y primeros años del xvir. El panorama es, pues, completamente distinto del que imaginaba Ioulché-Delbosc.

Tras esto, debo decir ${ }^{1}$ que a mí, lector, La Estrella dc Sevilla no me da la impresión de Lope. Iil juicio de Menéndez. Pelayo, de estar mejor pensada que escrita, cs intocable. Tampoco deja de hacer fuerza el análisis de la versifjcación hecho

1 Vé.se wús arriba, pier ; I. 
por Morley y Bruerton, que para ellos prueba awithout question" no ser de Lope. Ciertamente que las anomalías respecto a la versificación habitual de éste son notables ${ }^{1}$.

In fin, la obra, tal como ha llegado a nosotros, no parece de I,ope, aunque no se debe desechar la posibilidad de un texto sumamente alterado por un refundidor. Es lo que supuso Menéndez Pelayo y lo que piensa Juliá ${ }^{2}$. Sea de esto lo que fuere, el argumento menos valido contra la paternidad de I,ope es el basado en el Cardenio final.

Ein cuanto a que el Cardenio de La Arcadia, de Lope, sea el mismo de Salas Barbadillo, y ambos don Pedro de Cárdenas y Angulo, ya el lector sabe, a estas alturas, que no puede ser ${ }^{3}$, y no vamos a repetir otra vez las razones.

CONSECUENCIAS.

De las dos listas precedentes, la de poetas de nombre Cárdenas y la de Cardenios que aparecen en literatura de la época, salen, inmediatamente, consecuencias importantes.

De la existencia de tanto Cárdenas poeta resulta que no se puede negar la posibilidad de que uno de esos Cárdenas u otro cualquier Cárdenas poeta, fuera el Cardenio de $L a E s$ trella. Se ha dicho que el autor debería buscarse entre los escritores famosos y conocidos. En verdad, posible; pero no hay que excluir tampoco la posibilidad de que fuera un escritor oscuro. Hay creadores de una sola obra. ¿Hasta cuándo se

1 Creo, sin embargo, que los ilustres investigadores norteamericanos hubieran hecho bicn en soncter a su anclisis tanto el texto del adesglose como el de la usuelta" (se laan limitado a lo primero). Las relaciones entre ambos textos cleberian ser aín sometidas a revisión. Algunas de las amomalias habrian disaparecido si se hubiera partido del texto de la "sualta". P'or ejemplo: el larguisimo romance que empieza en el verso 2 I $7+$ casi se lubiera reducido en una tercera parte.

2 Obras dramáticas..., de I.ope, ed. Biblioteca Clásica, tomo 269." pán. XX.

3 Tampoco considero nada verosinil que cl Cardenio de Gálvez de Montalvo (1582) represente la misura persona que el de I,ope (1598). 
va a negar a Fernández de Andrada la paternidad de la Epistola moral, a pesar de que toda una serie de manuscritos nos asegure que es él el autor? ¡Ojalá estuvieran tan comprobadas otras atribuciones que nadie discute!

Más importante es, a mi juicio, lo que se deduce de la segunda lista. Cardenio como nombre literario no era ni muy frecuente ni muy raro. No era, claro, un privilegio de familia, reservado a los Cárdenas: un día a Lope le dió la real gana de llamarse Cardenio, y se lo llamó; otro día fué a Salas Barbadillo a quien le plugo encubrirse bajo el nombre de Cardenio, y lo hizo.

En resumen: I) Si pensamos que bajo el Cardenio de $L a$ Estrella ha de haber un Cárdenas, tenemos poetas Cárdenas a porrillo, y no hay razón ninguna para aferrarnos a que ha de ser precisamente Cárdenas y Angulo. 2) Pero, pensar que bajo el Cardenio haya forzosamente un Cárdenas, es absurdo, puesto que hay un Cardenio que representa a Lope y otro a Salas Barbadillo.

Consecuencia final: bajo el Cardenio de La Estrella de Sevilla puede ocultarse cualquier poeta que escribiera en España a principios del siglo xvir. ¿Parece muy amplio? Pues lo reduciré así: creo que ese poeta o era de Sevilla o había vivido en Sevilla bastante tiempo.

Entre tantos Cárdenas poetas y Cardenios poetas, ¿por qué lanzarse a atribuir La Estrella de Sevilla a don Pedro de Cárdenas y Angulo, cordobés (su vida, por lo que sabemos, transcurre entre Córdoba y Madrid ${ }^{1}$, cuyas características como poeta coinciden con las de su señoril personalidad humana: refinamiento, distinción, nada parecido a la rapidez de hechura y a la despreocupación volandera del hombre de tea-

1 De tres viajes entre Córdoba y Madrid tenemos noticin: el primero, cuando en la primavera de $16 r_{3}$ llevó a Madrid la primera versión del Polifemo y de las Soledudes (en realidad, la Primera Soledad: véase "Las Soledades", nuevamente publicadas por D. Alonso, Madrid, 1935, pág. 313 y sigs.). Para los otros dos viajes, véase más abajo, págs. 89-9o, texto y $90 \mathrm{n}$. 1 . 
tro? Y no se objete o especule con esa comedia que don Pedro escribió en colaboración con Parecles. El fragmento, impreso en las Rimas ${ }^{1}$, delicadamente poético, es nulo y muerto aesde un punto de vista teatral; nos trae a la memoria la ineficacia escénica de tanto fino poeta: ahí está don I, uis de Góngora con Las firmezas de Isabcla y El doctor Carlino, si se quiere un ejemplo.

Abolorio de CÁrdenas y Angulo.

He aquí la genealogía de don Pedro según sus pruebas para el hábito de Santiago:

Padres: Hernan darias de Saabedra y Caycedo Cau ${ }^{\circ}$ de la orden de $S^{\circ}$ y cofrade de la caridad de Jesu Xpo de la dha ciu ${ }^{d}$ y nral. della

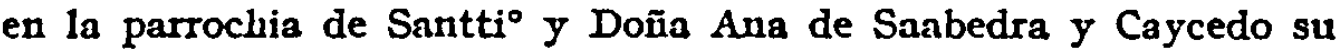
muger.

Abuelos paternos: Don $\mathrm{P}^{\circ}$ de Cardenas $\mathrm{Vez}^{\circ}$ y veintiq ${ }^{\circ}$ de Corda y Doña Cata de Angulo, su muger.

Abuelos maternos: Martin de Caycedo y Saabedra vez ${ }^{\circ}$ y veintiquatro de Cordoua en la Collon de la Magdalena y cofrade de la caridad de Jesu Xpo y Doña Catalina de Cardona su muger.

Son todos vezinos y nrales de la ciu de Cordoua.

Por las declaraciones de varios testigos sabemos que la madre de don Pedro vivía aún. El testigo I2. ${ }^{\circ}$ (Francisco Carri110 de Córdoba) nos dice que Hernandarias Saavedra y Caicedo (padre del pretendiente) cambió de nombre al casarse: «antes de casado se llamaba don Juan de Angulo de Cárdenasn y que la abuela del pretendiente, doña Catalina de Angulo, hacla muy poco que había muerto umonja en el conbento de Regina, de esta ciudad" ${ }^{2}$.

1 Ed. cit., págs. 64-69. D. Pedro de Cárdenas envió un soneto a la justa sevillana de 1623 (véase Encomio..., fol. $29 \mathrm{r}^{\circ} \mathrm{Y} \mathrm{v}^{\circ}$ ): es obra culta, gongorina.

- Ramirez de Arellano en su libro Juan Rufo, Jurado de Córdobn, Madrid, I912 (págs. 289-293), publicó vatios documentos de los protocolos cordobeses, relativos a don Pedro de Cárdenas, el abuelo paterno de nuestro Cárdenas y Angulo. Pero Ramirez de Arellano se 
LAS POESÍAS DE GÓNGORA a CíRDENAS Y ANGULO.

Se suelen citar dos sonctos de Góngora a don Pedro de Cárdenas y Angulo (Millé, 33 I y 335). Se olvida, a veces, ell cambio, una décima (Millé, I55) con ocásión de que un toro le hubiera matado a don Pedro un caballo llanado Frontalete. Otro caballo suyo se llamaba Zagal, según el soneto nímero 33r. A toros y caballos, y, en general, a fiestas en que interviniera la equitación, era muy aficionado don Pedro: así se comprende el encargo de elegir los caballeros para los toros y cañas que el Marqués del Carpio había de ofrecer en su es-

equivoca al creer que este don Pedro de Cárdenas cra el padre de unestro poeta: la genealogfa transcrita, en el texto, de las pruebas para $\mathrm{Cl}$ hábito, no deja lugar a duda. Este abuelo de Cárdenas y Angulo testó en 1580. En Ramirez de Arellano se mezclan los datos útiles con las más desaforadas fantasias. Asi, por ejemplo, imagina que un Antonio Fernández de Cárdenas (perteneciente, tal rez, a la misma familia) pucda ser el Cardenio del Quijote. ¿Base? El hecho que ya vinos, de que en la primera edición se lea "Don Antonio", en vez de "Cardenio" al comienzo del cap. XLII de la primera parte. Ramirez de Arellano no encontró otro Cárdenas de nombre Antonio sino ése. ¡Pues cátatele Cardenio! Lo pintoresco es que a renglón seguido parece arrepentirse: decide entonces que Luscinda sería la de apellido Cárdenas (una Luisa de Cárdenas); en cuanto a Cardenio... iquién seria Cardenio? Nada nenos que don Luis de Góngora (píg. 292). ¡Estupendo! Y también es estupenda la historia, que cuenta a continuación, de un rapto intentado por don Luis en la persona de una hermana de Cárdenas y Angulo, patraña que ya rectificó Artigas, Don Luis de Gúngora, págs. 48-49 (pero téngase en cuenta lo que dice don José de lit Torre en Bol. de la R. Acad... de Córdoba, 1927, págs. 68-69). No me detendré ni en rechazar la especie, defendida por Bonilla, de que Cardenio fuera Cristóbal Calderón: pertenece a la más desvirriatla fintiasia. (Véase Fitzmaurice-Kelly, Hist. de la Lit. Esp., traducilla y arotada por Adollo Bonilla San Martin [1. ${ }^{n}$ ed.], Madrid, s. a., pág. 327, nota. Otro error que se ha cometido algunas veces es el de confundir a don Pedro de Cárdenas y Angulo con don Pedro Jacinto de Cárdenas y Angulo, que en 165x publicó unas reglas para torear a caballo (V.: Biblibfilos Españoles, 2.` época, XVIII, págs. gr-122). 
tado a Ielipe IV (durante el viaje real a Andalucía, I624 ${ }^{1}$ ). I'a hemos dicho que los testigos de las pruebas para el hábito insisten con especial énfasis en estas aficiones de don Pedro.

El soneto de Góngora "Hojas de inciertos chopos el nevado" (Millé, 335) ha sido interpretado mal, desde el mismo siglo xvir. En Vicuña, el título es "A don Pedro de Cárdenas y Angulo, estando en Granada, año I6r6 que fué de agua esteril»; en Chacón, "A un caballero de Córdoba que estaba en Gräladan, y se adjudica a I6r5. Basta, sin embargo, leer el soneto para darse cuenta de que don Pedro no estaba en Granada, sino que partía para esa ciudad. Sólo Salcedo Coronel lo vió; dice ken ocasión que iba [don Pedro] a cierto pleyto, a la ciudad de Granada, el año de 1615, que fué muy secon.

\section{DÁmaso Aronso}

1 Ramirez de Arellano, I, pág. to7 a. El mismo Juan Páez de Valenzuela, que es quien da esa noticia, nos dice que don Pedro era Caballerizo de Su Majestad. No es aventurado imaginar que cuidara de aprovisionar en Córdoba (famosa por sus caballos) las cuadras reales. El siguiente documento inédito nos le muestra en noviembre de I626 en Córdoba por "orden", y con derecho a cobrar sus gajes durante esta ausencia:

Don Pedro de Cárdenas y Angulo está con licencia en Córdoba. Mandad que se note assí y se le dé el despacho necessario para que pueda cobrar lo que se le deue y fuere cayendo de sus gajes durante esta ausencia, pues la liaze con licencia y orden. Dios os guarde como desseo. Del Aposento, a 28 de Noviemibre de 1626. (Oficio dirigido al Marqués de Flores.-Archivo de Palacio, Personal, legajo C-2o. $\Lambda$ gradezco a la Srta. Fismeralda Gijón la rebusca hecha, a mi ruego, cn ese archivo.)

$A D I C I O{ }^{\prime}$ - En el cartapacio de P. de Penagos (M. Pidal, $B R A E^{\circ}$ I, 1914, pág. 316) hay ell el fol. 185 un Romance de Carrión. Tratase de los amores de un Cardenio y una Clenarda (Cardenio vivió una época junto al Ebro, canta alıra junto al Miño, etc.). I,o intercsante es esto: $C \wedge$ Rdenas, Vega $C A R$ pio y $C A R$ rión, los tres, han usado cl seudónimo o nombre poético rle CARdenio. Parece, pues, que el solo hecho de empezar por CAR- era un incentivo para usar tal seudónimo. IIe ahí otra pista para buscar posibles Cardenios. 